\title{
'||||||||||||||||||||||||||||||||||||||||||||||||||||||||||||||||||.
}

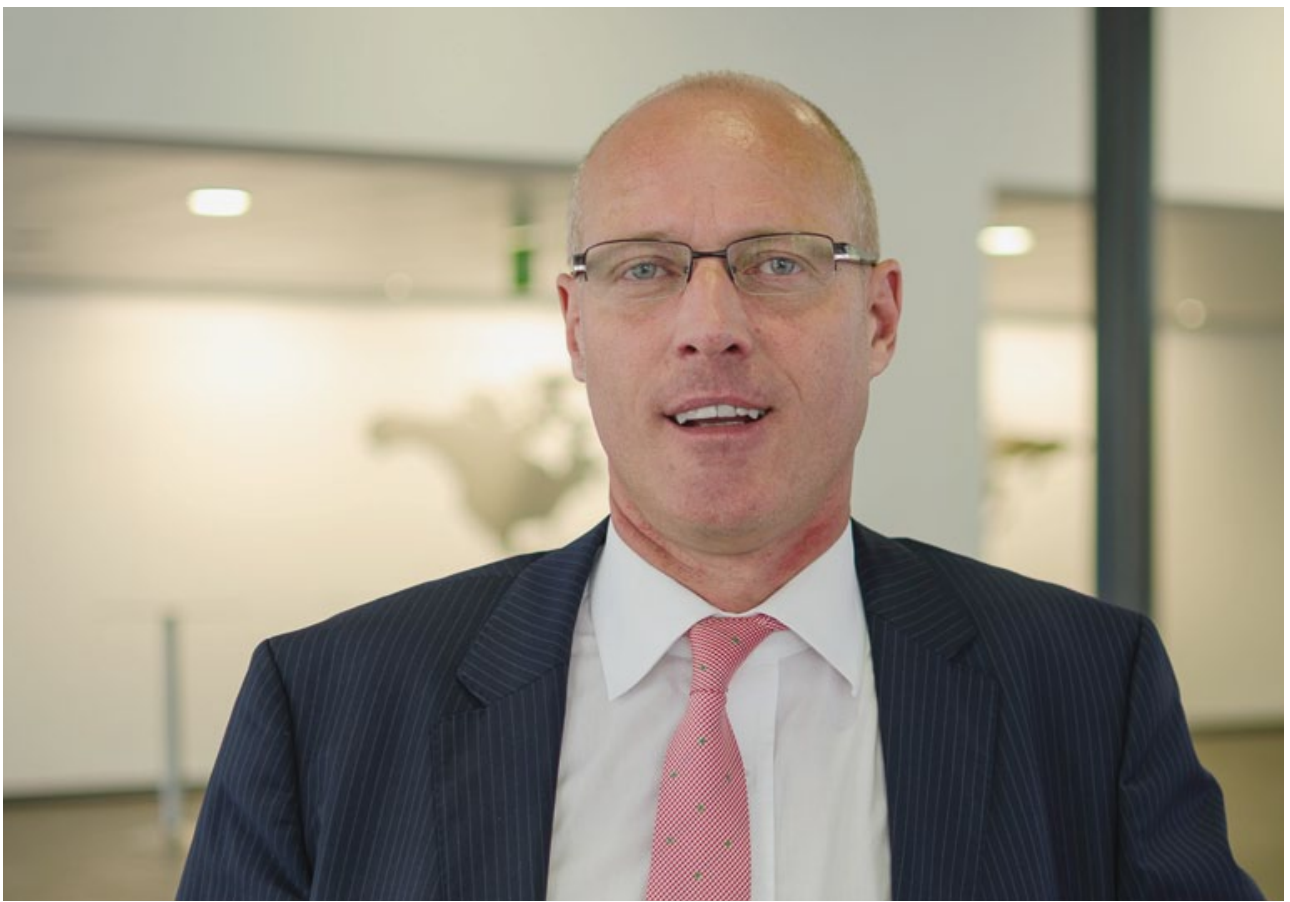

PROF. DR.-ING. JÜRGEN HAMMER

Senior Vice President

Engineering Business Unit

Passenger Cars and Light Duty,

Bosch Diesel Systems

\section{GRENZEN MANAGEN}

Steigende Anforderungen an künftige Fahrzeugantriebe, wie minimaler Verbrauch, Erfüllung strengster Emissionsgrenzwerte, begeisternde Leistungsentfaltung und höchster Komfort, um nur einige beispielhaft zu nennen, stellen an die Motorsteuerungssysteme stets weiter steigende Funktionsanforderungen. Dies gilt für alle Arten von Antriebssträngen gleichermaßen, einschließlich der hier zum Einsatz kommenden komplexen Motorsteuerungssysteme, wie etwa der Kraftstoffeinspritzung oder des Luftsystems mit Aufladeaggregaten. Auf Bauteilebene münden diese Anforderungen zwangsläufig in Fertigungsfähigkeiten, die definitiv als grenzwertig zu bezeichnen sind.

Ein Beispiel dazu aus dem Bereich der Aufladung ist die Akustik. Hier gilt ein besonderes Augenmerk den Lagerspielen des Turboladers, der mit bis zu 300.000/min dreht. Durch eine gezielte Auslegung lässt sich hier der für das menschliche Ohr als unangenehm wahrgenommene Konstantton erheblich reduzieren. Maßgeblichen Einfluss auf das Lagerspiel haben die Durchmessertoleranzen von Buchse und Welle, die mittlerweile mit weniger als $\pm 2 \mu \mathrm{m}$ gefertigt werden müssen.

Um dem Fortschritt den Weg weiter frei zu machen, sind wir Ingenieure gefragt, uns diesen Anforderungen mit Lösungen zu stellen, auch wenn dabei zuweilen der Eindruck entsteht, es seien nun Grenzen erreicht, die Lösungen verlangen, welche sich nicht mehr sinnfällig zu adäquaten Kosten darstellen lassen. Was tun mit diesen Grenzen? Ein Ansatz kann sein, diese Grenzen früh zu erkennen, zu managen und schließlich zu verschieben.
Aus Projektsicht kommt dem „früh Erkennen“ eine zentrale Rolle zu. Basierend auf den gründlich definierten Anforderungen muss bei der Konzeptdefinition auf System- und Komponentenebene darauf geachtet werden, dass sich das Konzept innerhalb bestehender Fertigungsgrenzen bezüglich Toleranzen und Veränderungen über Laufzeit noch trägt.

Stößt solches Vorgehen konzeptunabhängig auf Komponentenebene an physikalische Grenzen oder lässt sich die Komponentenfunktion nicht mehr wirtschaftlich sinnvoll darstellen, greift der systemische Ansatz des „Grenzen managen“. Hier teilen sich die Lasten auf die Schultern der Komponente und deren Ansteuerung über Modelle und Algorithmen. Während die Komponente das Machbare oder wirtschaftlich Sinnvolle darstellt, verlagert das System die funktionale Erfüllung der funktionsbestimmenden Größen im System auf seine Ebene. Durch flankierende Sensorik nutzen die Systemfunktionen messbare Größen, um die Komponente in ihrer Streuung und Veränderung über Laufzeit zu erkennen und zu korrigieren.

Last but not least liefern gänzlich neue Produktkonzepte, die sich zum einen neuer Werkstoffe bedienen und zum anderen innovative Fertigungsprozesse nutzen, neue Wege, um heute gesteckte Grenzen zu erweitern. Hier ist jedoch stets ein langer Weg auch auf der Kostenachse zu gehen, bis solche Innovationen vollständig etabliert sind. Eins scheint sicher: Grenzen sind nicht starr, also lassen Sie uns diese weiter verschieben! 